\title{
Heat Loss Test and Estimate for the Large-scale Floating Roof Tank
}

\author{
Jian Zhao*, Hang Dong, Li X. Wei and Yang Liu \\ Oil and Gas Transportation and Storage Department, Northeast Petroleum University, Daqing, 163318, P.R. China
}

\begin{abstract}
The heat loss and surface temperature of the top surface and sidewall of large-scale floating roof tank is tested by the heat flow meter and surface temperature method. Based on the test data, the heat loss from the top surface is about twice more than that of the sidewall which means the top surface is the weakest insulation part of the floating roof tank. On the surface, the heat loss profile is in accord with the surface temperature distribution. Special attention is given on the calculation of thermal conductivity for the top surface and sidewall which finally deduced the total heat transfer coefficient of large floating roof tank. Moreover, the heat loss of floating roof tank in different working conditions is predicted. According to the calculation results, the level of $6 \mathrm{~m}$ is regarded as a critical level determining the heat loss. And the centralization storage of oil is a more energy conservation storage pattern.
\end{abstract}

Keywords: Floating roof tank, heat loss, test, total heat transfer coefficient.

\section{INTRODUCTION}

Nowadays, in order to avoid the energy crisis, an increasing attention is given on the energy storage in many countries. As one of the most important primary energy, the storage of crude oil always dominates in the existing energy system. With the increasing storage scale of crude oil, the heat dissipation during the storage course draws many people's attention. Especially in the cold region, for the storage of waxy crude oil, the heat loss is considerable. For many large crude oil depot, the floating roof tank has become the preferred facility to store oil. But due to the specific construction, the heat loss from the different part of the tank is difficult to ascertain.

Normally, the theoretical calculation based on the heat transfer theory is induced to investigate the heat loss, Busson and miniscloux [1] developed a simple model to predict the steady state heat losses from a fuel oil tank based on the assumption of a well-mixed core of fluid. Kumana and Kothari [2] proposed empirical correlations for heat transfer coefficients of the tank and published a model to predict the cooling rate of oil. Venart [3] solved the governing natural convection equations to investigate the steady state heat losses from a fuel oil tank. Cotter and Michael [4-6] presented a simplified heat loss model based on the numerical calculation of heat transfer in the oil tank. Moreover, the effect of heat transfer coefficient, aspect ratio and temperature dependent viscosity on the fluid flow and heat transfer was examined. In general, most research takes the dome roof tank as the research object, the heat loss rule of which is very different from the float roof tank due to the different roof construction. Together with the complex heat transfer course which is difficult to characterized, the actual measurement is still regarded as the most effective method.
As mentioned above, the actual measurement of heat loss from floating roof tank has not been reported in the literature. The aim of this work is to investigate the heat loss from the different part of the floating roof tank, and special attention is given on the heat flux from the top surface and the calculation of thermal conductivity for air layer in the top surface. The surface temperature of the tank is also tested to estimate the inner temperature profile of oil. Moreover, the total heat transfer coefficient of large floating roof tank is proposed to predict the heat loss in different working condition which is significant for the management of the oil depot, in the meantime provides the basis for the energy-saving and efficient storage of crude oil.

\section{EXPERIMENTAL STUDIES}

\subsection{Test Principles}

The test of the floating roof tank is based on the steadystate heat transfer hypothesis. Although the temperature of oil in the tank changes during the storage course, due to the large scale and large quality of oil, the temperature varies very slowly and in the stable environmental conditions, the steady-state hypothesis is regarded acceptable. On the top surface, the roof of the tank is constituted by two thin steel plates with an air interlayer between them. The heat transfer process is illustrated in Fig. (1), which can be simplified as the one-dimensional heat transfer in the normal direction through the plan wall. While on the sidewall, the heat transfer process can be simplified as the one-dimensional heat transfer in the normal direction through the cylindrical wall, shown in Fig. (2).

On account of the steady-state heat transfer, the heat flow from the oil to the inside wall of the air layer is the same as it from the outside wall of the air layer to the air, which can be expressed as follows:

$$
q_{\text {ding }}=h_{1}\left(t_{\text {oil }}-t_{1 \mathrm{bi}}\right)=\frac{\lambda_{\text {air layer }}}{\delta_{\text {air layer }}}\left(t_{1 \mathrm{bi}}-t_{2 \mathrm{bi}}\right)=h_{2}\left(t_{2 \mathrm{bi}}-t_{\mathrm{qi}}\right)
$$


Where $q_{\text {ding }}$ is the heat flow from the oil inside the tank to the outside surroundings, $\mathrm{W} / \mathrm{m}^{2} ; h_{1}$ is the convective heat transfer coefficient between the oil and the inside wall of top surface, $\mathrm{W} / \mathrm{m}^{20} \mathrm{C} ; h_{2}$ is the convective heat transfer coefficient between the outside wall and the surroundings, $\mathrm{W} / \mathrm{m}^{20} \mathrm{C} ; \lambda_{\text {airlayer }}$ is the thermal conductivity of the air layer, $\mathrm{W} / \mathrm{m}{ }^{\circ} \mathrm{C} ; \delta_{\text {air layer }}$ is the thickness of air layer, $\mathrm{m}$; $t_{\mathrm{oil}}, t_{1 \mathrm{bi}}, t_{2 \mathrm{bi}}$ are the temperature of oil in the core of the tank, the temperature of the inside wall of the top surface, the temperature of the outside wall of the top surface, ${ }^{\circ} \mathrm{C} ; t_{\mathrm{qi}}$ is the temperature of the surroundings, ${ }^{\circ} \mathrm{C}$.

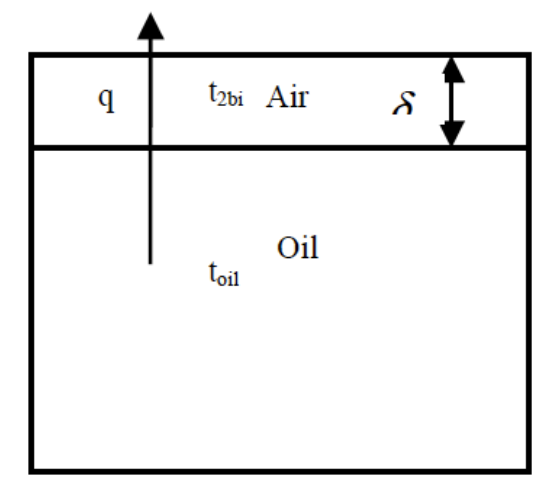

Fig. (1). Heat transfer process on floating roof.

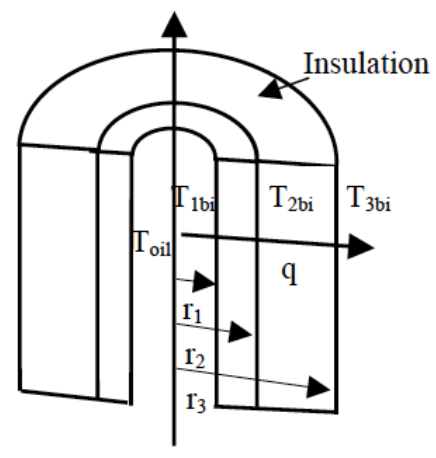

Fig. (2). Heat transfer process at sidewall.

For the sidewall, the heat flow from the oil to the inside wall is the same as it from the outside wall to the air, which can be expressed as follows:

$$
\begin{aligned}
& \phi_{\mathrm{bi}}=\left(\pi d_{1} H\right) h_{1}\left(t_{\mathrm{oil}}-t_{\mathrm{bbi}}\right)=\frac{2 \pi H\left(t_{\mathrm{bbi}}-t_{3 \mathrm{bi}}\right)}{\ln \left(d_{2} / d_{1}\right) / \lambda_{\mathrm{bil}}+\ln \left(d_{3} / d_{2}\right) / \lambda_{\mathrm{bi} 2}} \\
& =\left(\pi d_{3} H\right) h_{2}\left(t_{3 \mathrm{bi}}-t_{\mathrm{qi}}\right)
\end{aligned}
$$

Where $\phi_{\mathrm{bi}}$ is the total heat loss from the oil inside the tank to the outside surroundings, $\mathrm{W} ; h_{1}$ is the convective heat transfer coefficient between the oil and the inside wall, $\mathrm{W} / \mathrm{m}^{20} \mathrm{C} ; h_{2}$ is the convective heat transfer coefficient between the outside wall and the surroundings, $\mathrm{W} / \mathrm{m}^{20} \mathrm{C} ; \lambda_{\text {bil }}, \lambda_{\text {bi2 }}$ are the thermal conductivity of the steel and the insulation, $\mathrm{W} / \mathrm{m}^{\circ} \mathrm{C} ; d_{1}, d_{2}, d_{3}$ are the inner diameter of the tank, inner diameter of the insulation, outside diameter of the insulation respectively, $\mathrm{m} ; H$ is the level of the tank, $\mathrm{m}$.

\subsection{Test Method}

The heat flow meter method and surface temperature method are both adopted in the heat transfer testing. The heat flow meter can be directly employed to test the heat flow from the surface of the wall. The test procedure is shown in Fig. (3). When the heat transfer reaches the steady state process, the heat flow from the sensor is regarded as the heat flow from the wall so that the heat flow data can be obtained directly. By the surface temperature method, based on the forced convective heat transfer correlations, the heat flow can be calculated in case that the wind speed, surface temperature and surrounding temperature are obtained.

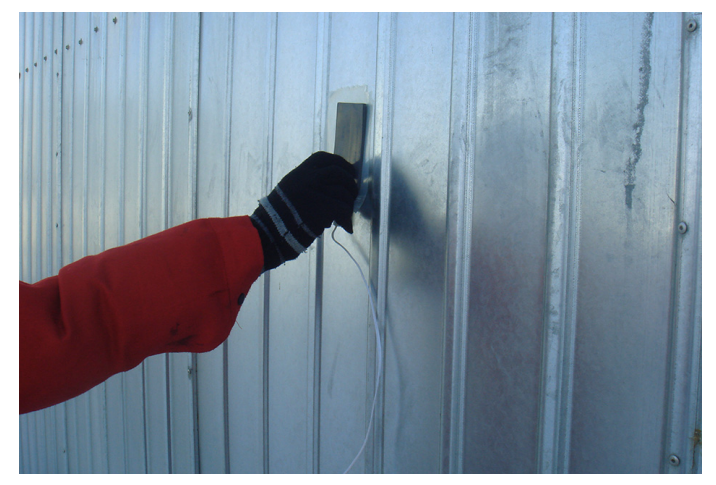

Fig. (3). Installation of heat flow meter probe.

The convection heat transfer between sidewall and atmosphere can be regarded as forced convection heat transfer when the air crossing the single pipe, the experiment correlation of which is as follows:

$$
\mathrm{Nu}=C \operatorname{Re}^{n} \operatorname{Pr}^{1 / 3}
$$

When the $\operatorname{Re}>500000$, the convection heat transfer between the top wall and atmosphere is considered as the forced convection heat transfer when the air swaying surface of the plate, the experiment correlation of which is as follows:

$$
\left.\mathrm{Nu}=\left(0.037 \mathrm{Re}^{4 / 5}-871\right) \operatorname{Pr}^{1 / 3}\right)
$$

Where $\mathrm{Nu}=\frac{h_{\mathrm{c}} l}{\lambda}, h_{\mathrm{c}}$ is the convective heat transfer coefficient between the surface and the atmosphere, $\mathrm{W} / \mathrm{m}^{20} \mathrm{C} ; \lambda$ is the thermal conductivity of air, $\mathrm{W} / \mathrm{m}^{\circ} \mathrm{C} ; l$ is the characteristic length, $\mathrm{m} ; \operatorname{Re}=\frac{u l}{v}, \operatorname{Pr}=\frac{v}{\alpha} ; C, n$ are the coefficients determined by Re; $u$ is the wind speed, $\mathrm{m} / \mathrm{s} ; v$ is the kinematic viscosity of air at the qualitative temperature, $\mathrm{m}^{2} / \mathrm{s}$; $\alpha$ is the thermal diffusivity of air at the qualitative temperature, $\mathrm{m}^{2} / \mathrm{s}$.

The conversion convective heat transfer coefficient of radiation heat transfer between the surface and atmosphere is calculated by the following formula:

$$
h_{\mathrm{r}}=\varepsilon \sigma\left(T_{w}^{2}+T_{\mathrm{qi}}^{2}\right)\left(T_{w}+T_{\mathrm{qi}}\right)
$$

Where $\varepsilon$ is the surface emissivity of structure, which is obtained from the test; $\sigma$ is the black-body radiation constant, $5.67 \times 10^{-8} \mathrm{~W} / \mathrm{m}^{2} \mathrm{~K}^{4} ; T_{w}$ is the outside temperature of the structure, $\mathrm{K}$. 


\subsection{Test Plan}

The test object is the top and sidewall of $10 \times 10^{4}$ and $5 \times 10^{4} \mathrm{~m}^{3}$ oil tank. The test objects are divided into different parts in order to investigate the distribution of the surface temperature and the heat flow in the mean time a more precision test result of the whole surface will be obtained by counting the data of different positions. The principle of dividing the test parts is to average the surface as much as possible. However, when the variation gradient of testing parameters in some local region is evident, the testing region will be redivided to get the variation tendency of the testing parameters.

Based on the heat flow meter method, the test tool is the portable heat flow meter of HFM-201. The probe of heat flow meter is directly attached on the surface and for a while the heat flow through the surface is obtained when the heat transfer is getting a steady state. For the surface temperature method, the surface temperature is tested by the surface thermometer HLC-60, the wind speed is tested by the intelligent anemograph of ZRQF series. For the sake of improving the test accuracy, the wind speed and atmosphere temperature are tested in the same time and $1 \mathrm{~m}$ away from the surface. In the mean time, triple tests for every test position are carried out to get the test result more precise. The insulation thickness and other data of the tank are obtained from the construction drawings. In order to avoid the effect from the sunshine, the test is carried out in cloudy day.

\section{TEST RESULT}

The test data include the surface temperature, heat flow, ambient temperature and wind speed, so that the temperature distribution of the surface can be obtained Fig. (4). Based on the steady state heat transfer hypothesis, the oil temperature in the tank is in accord with the surface temperature so that the surface temperature distribution reflects the profile of oil temperature near the inside wall. In the mean time, the heat flow of different positions directly reflects the heat loss and insulation effect of different positions.

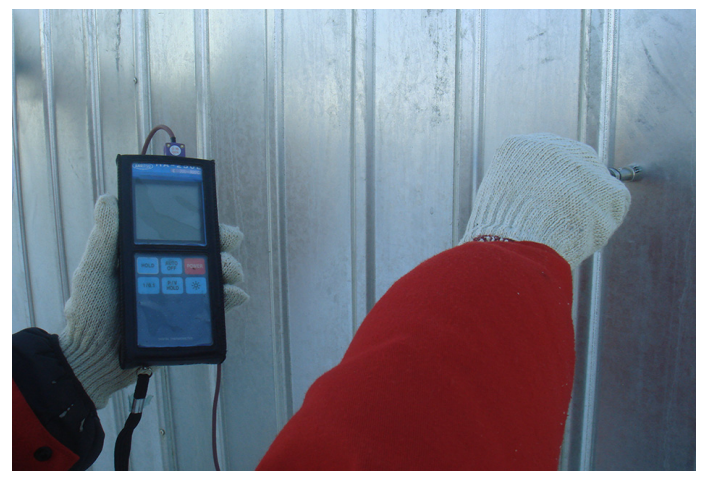

Fig. (4). Temperature test on the surface.

\subsection{The Test Result of Surface Temperature}

In general, due to the difference of insulation effect, the surface temperature of top wall is higher than that of the sidewall, the test data is listed in Table $\mathbf{1}$.

The roof of tank is constituted by two thin steel plates with an air interlayer between them. Although the thermal conductivity of air is rather small, the heat conducting property is enhanced by the natural convection and the steel structure in the enclosure space. For the side wall, the special insulation material is installed on the tank, leading a better insulation effect. Besides, the temperature varies with different positions Fig. (5).

Table 1. Average surface temperature on different positions.

\begin{tabular}{|c|c|c|c|c|}
\hline $\begin{array}{c}\text { Specification } \\
\left(\mathbf{m}^{3}\right)\end{array}$ & $\begin{array}{c}\text { Level } \\
\text { (m) }\end{array}$ & $\begin{array}{l}\text { Oil T } \\
\left({ }^{\circ} \mathrm{C}\right)\end{array}$ & Position & $\begin{array}{c}\text { Average T } \\
\left({ }^{\circ} \mathrm{C}\right)\end{array}$ \\
\hline \multirow{2}{*}{$5 \times 10^{4}$} & \multirow{2}{*}{11.93} & \multirow{2}{*}{45} & sidewall & -13.30 \\
\hline & & & topwall & -7.59 \\
\hline \multirow{2}{*}{$10 \times 10^{4}$} & \multirow{2}{*}{12.75} & \multirow{2}{*}{42} & sidewall & -14.67 \\
\hline & & & topwall & -7.96 \\
\hline
\end{tabular}

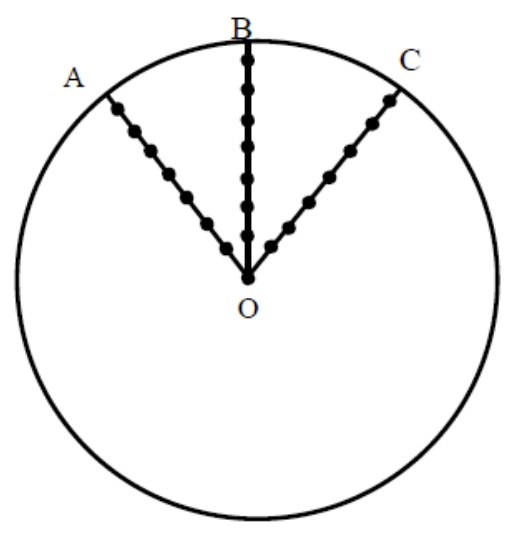

Fig. (5). Profile of test points along the radial direction.

The profile of surface temperature on the tank roof is shown in Fig. (6) and Fig. (8), Fig. (5) and Fig. (7) are the distribution of test points on tank roof. From the test data, the temperature decreases along the radical direction in general. But on some certain positions, where the oil inlet corresponds to, the surface temperature is higher than other positions on the same radial position. Based on the steady state heat transfer, the surface temperature reflects the oil temperature near the inner wall of the roof.

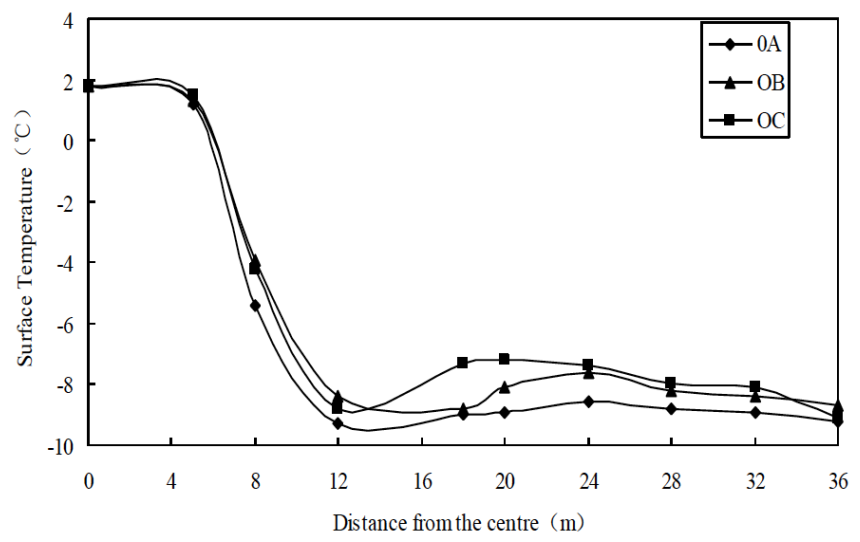

Fig. (6). Profile of temperature along the radial direction. 


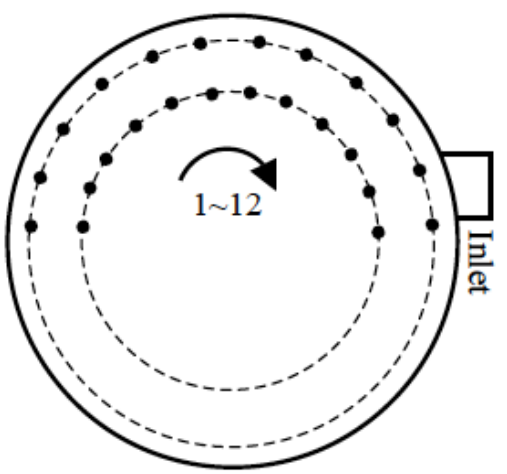

Fig. (7). Profile of test points along circumferential direction.

On the sidewall, the test positions are arranged along the escalator, the temperature profile is illustrated in Fig. (10) and Fig. (11), and Fig. (9) are the test point distribution. According to the test data, the surface temperature is lower on the top and on the bottom surface. In the middle part, the surface temperature is much higher and homogeneous. This temperature profile is in accord with the oil temperature near the inner wall. Near the top surface, the heat loss is more prominent, the oil temperature is much lower than that of the middle part, and due to the nature convection in the tank, the cold oil descends to the bottom so that near the bottom, the oil temperature is also much lower than the middle part.

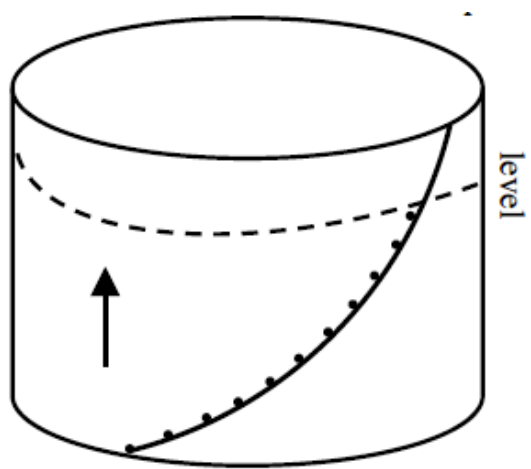

Fig. (9). Profile of measuring points.

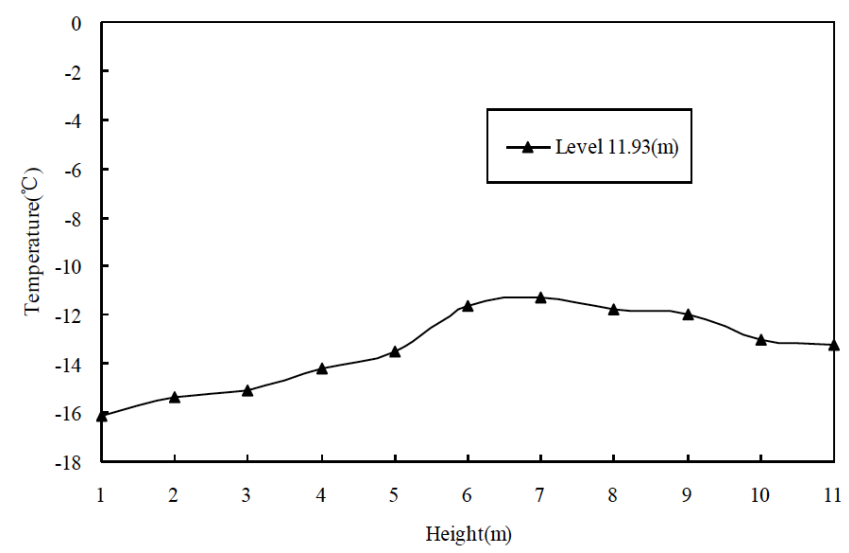

Fig. (10). Profile of temperature at sidewall $\left(5 \times 10^{4} \mathrm{~m}^{3}\right)$.

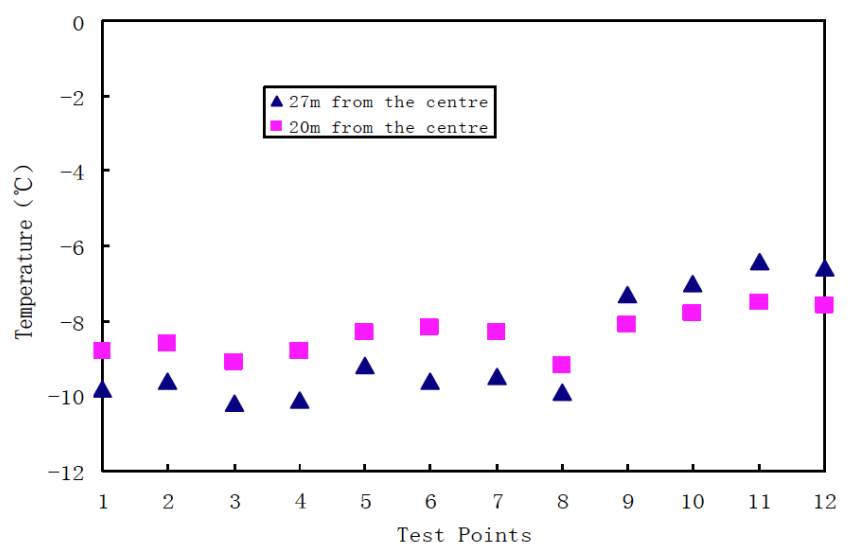

Fig. (8). Profile of temperature along circumferential direction.

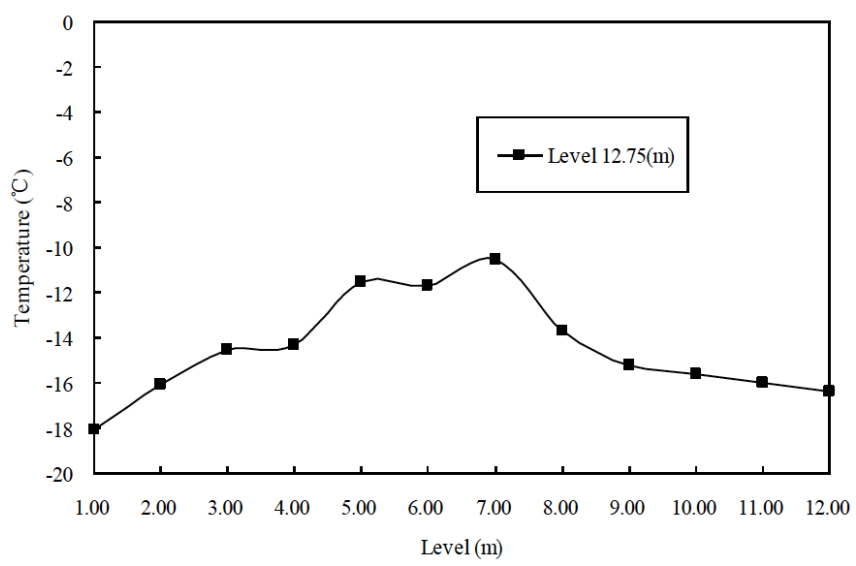

Fig. (11). Profile of temperature at sidewall $\left(10 \times 10^{4} \mathrm{~m}^{3}\right)$.

\subsection{The Test Results of Heat Flow}

The tank roof is divided into different parts to reflect the surface heat flow. For the $5 \times 10^{4} \mathrm{~m}^{3}$ tank, the top wall is divided into three parts, there are the center roundness region, and two annular regions. The $10 \times 10^{4} \mathrm{~m}^{3}$ tank is divided into four parts. The region partition on tank roof is shown in Fig. (12) and Fig. (13), test results are listed in Table 2 and Table 3.

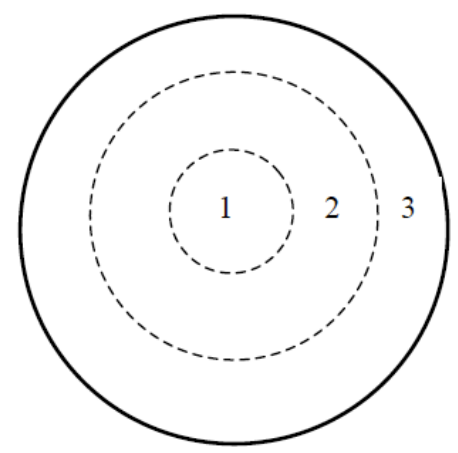

Fig. (12). Region partition on tank roof $\left(5 \times 10^{4} \mathrm{~m}^{3}\right)$.

For the sidewall, the test region is divided along the axis of tank. Every two meters are divided into one test region. The test tanks are divided into 6 parts shown in Fig. (14). And the test data are shown in Table $\mathbf{4}$ and Table $\mathbf{5}$. 


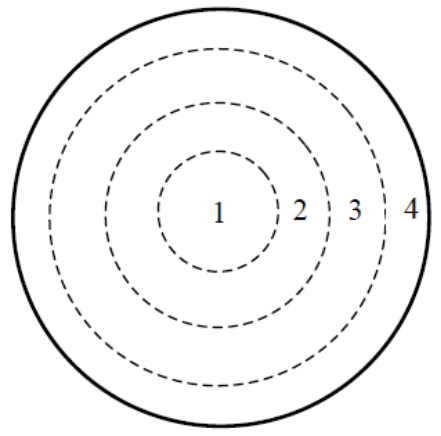

Fig. (13). Region partition on tank roof $\left(10 \times 10^{4} \mathrm{~m}^{3}\right)$.

Table 2. Heat flow of tank roof $\left(5 \times 10^{4} \mathrm{~m}^{3}\right)$.

\begin{tabular}{|c|c|c|c|c|c|}
\hline Region & $\begin{array}{c}\text { Area } \\
\left(\mathbf{m}^{2}\right)\end{array}$ & $\begin{array}{c}\text { Surface } \\
\mathbf{T}\left({ }^{\circ} \mathbf{C}\right)\end{array}$ & $\begin{array}{c}\text { Ambient } \\
\mathbf{T}\left({ }^{\circ} \mathbf{C}\right)\end{array}$ & $\begin{array}{c}\text { Wind } \\
\text { Speed } \\
(\mathbf{m} / \mathbf{s})\end{array}$ & $\begin{array}{c}\mathbf{Q} \\
\mathbf{W} / \mathbf{m}^{2}\end{array}$ \\
\hline \hline 1 & 314 & -2.73 & -17.50 & 1.2 & 82.73 \\
\hline 2 & 942 & -7.28 & -17.50 & 1.2 & 56.59 \\
\hline 3 & 1570 & -8.76 & -17.50 & 1.2 & 48.19 \\
\hline Average & & -7.59 & -17.50 & 1.2 & 54.83 \\
\hline
\end{tabular}

Table 3. Heat flow of tank roof $\left(10 \times 10^{4} \mathrm{~m}^{3}\right)$.

\begin{tabular}{|c|c|c|c|c|c|}
\hline Region & $\begin{array}{c}\text { Area } \\
\left(\mathbf{m}^{\mathbf{2}}\right)\end{array}$ & $\begin{array}{c}\text { Surface } \\
\mathbf{T}\left({ }^{\circ} \mathbf{C}\right)\end{array}$ & $\begin{array}{c}\text { Ambient } \\
\mathbf{T}\left({ }^{\circ} \mathbf{C}\right)\end{array}$ & $\begin{array}{c}\text { Wind } \\
\text { Speed } \\
(\mathbf{m} / \mathbf{s})\end{array}$ & $\begin{array}{c}\mathbf{Q} \\
\mathbf{W} / \mathbf{m}^{2}\end{array}$ \\
\hline \hline 1 & 314 & -0.46 & -19.60 & 0.7 & 83.39 \\
\hline 2 & 942 & -8.42 & -19.60 & 0.7 & 47.43 \\
\hline 3 & 1570 & -8.09 & -19.60 & 0.7 & 48.89 \\
\hline 4 & 2198 & -8.73 & -19.60 & 0.7 & 46.06 \\
\hline Average & & -7.96 & -19.60 & 0.7 & 49.54 \\
\hline
\end{tabular}

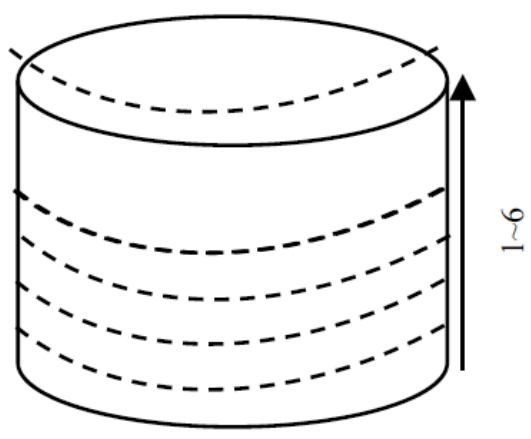

Fig. (14). Test regions at sidewall.

According to the test data, the distribution of the heat flow is in accordance with the surface temperature. The higher surface temperature corresponds to a higher heat flow, and vice versa. The average heat flow on the top wall is large than that of the sidewall, which is illustrated in Fig. (15). The area of the top wall is larger than that of the sidewall, leading the top wall become the main heat loss parts of the tank (shown in Fig. (16)), although the heat loss from tank bottom is not tested. The heat conduction is the main heat transfer form of the bottom wall, the heat loss of which is lower than the top wall and sidewall where the heat convection and conduction are the main heat transfer form. Moreover, the heat transfer surroundings for the top wall and sidewall are the atomosphere, while the soil is the heat transfer surroundings of the bottom wall the temperature of which is higher than the atomosphere during the test period. Finally, the heat loss distribution in the tank is top wall $>$ sidewall $>$ bottom.

Table 4. Heat flow of sidewall $\left(5 \times 10^{4} \mathrm{~m}^{3}\right)$.

\begin{tabular}{|c|c|c|c|c|c|}
\hline Region & $\begin{array}{c}\text { Area } \\
\left(\mathbf{m}^{2}\right)\end{array}$ & $\begin{array}{c}\text { Surface } \\
\mathbf{T}\left({ }^{\circ} \mathbf{C}\right)\end{array}$ & $\begin{array}{c}\text { Ambient } \\
\mathbf{T}\left({ }^{\circ} \mathbf{C}\right)\end{array}$ & $\begin{array}{c}\text { Wind } \\
\text { Speed } \\
(\mathbf{m} / \mathbf{s})\end{array}$ & $\begin{array}{c}\mathbf{Q} \\
\mathbf{W} / \mathbf{m}^{2}\end{array}$ \\
\hline \hline 1 & 376.8 & -15.74 & -18.80 & 1.10 & 14.55 \\
\hline 2 & 376.8 & -14.48 & -18.80 & 1.10 & 20.62 \\
\hline 3 & 376.8 & -13.10 & -18.80 & 1.10 & 27.32 \\
\hline 4 & 376.8 & -11.14 & -18.80 & 1.10 & 36.91 \\
\hline 5 & 376.8 & -12.25 & -18.80 & 1.10 & 31.46 \\
\hline 6 & 376.8 & -13.10 & -18.80 & 1.10 & 27.32 \\
\hline Average & 376.8 & -13.30 & -18.80 & 1.10 & 26.36 \\
\hline
\end{tabular}

Table 5. Heat flow of sidewall $\left(10 \times 10^{4} \mathrm{~m}^{3}\right)$.

\begin{tabular}{|c|c|c|c|c|c|}
\hline Region & $\begin{array}{c}\text { Area } \\
\left(\mathbf{m}^{2}\right)\end{array}$ & $\begin{array}{c}\text { Surface } \\
\mathbf{T}\left({ }^{\circ} \mathbf{C}\right)\end{array}$ & $\begin{array}{c}\text { Ambient } \\
\mathbf{T}\left({ }^{\circ} \mathbf{C}\right)\end{array}$ & $\begin{array}{c}\text { Wind } \\
\text { Speed } \\
(\mathbf{m} / \mathbf{s})\end{array}$ & $\begin{array}{c}\mathbf{Q} \\
\mathbf{W} / \mathbf{m}^{2}\end{array}$ \\
\hline \hline 1 & 502.4 & -17.09 & -22.20 & 1.10 & 23.29 \\
\hline 2 & 502.4 & -14.97 & -22.20 & 1.10 & 33.18 \\
\hline 3 & 502.4 & -12.50 & -22.20 & 1.10 & 44.81 \\
\hline 4 & 502.4 & -12.30 & -22.20 & 1.10 & 45.76 \\
\hline 5 & 502.4 & -15.17 & -22.20 & 1.10 & 32.24 \\
\hline 6 & 502.4 & -16.00 & -22.20 & 1.10 & 28.35 \\
\hline Average & 502.4 & -14.67 & -22.20 & 1.10 & 34.61 \\
\hline
\end{tabular}

\subsection{The Heat Conduction of the Tank Wall}

On condition that the heat flow, the surface and oil temperature is known, the thermal conductivity of the top wall and sidewall can be calculated. For the test tank, the calculation result is listed in Table 6. The air layer is the main insulation structure of the top wall the thermal conductivity of which is much larger than the sidewall. The thermal conductivity of air is $0.023 \mathrm{~W} / \mathrm{mK}$, however the heat convection and steel structure enhanced this heat transfer intensity by about 30 times. The insulation material of sidewall for $5 \times 10^{4} \mathrm{~m}^{3}$ tank is rock wool, while the insulation material of sidewall for $10 \times 10^{4} \mathrm{~m}^{3}$ tank is hard silicate. 


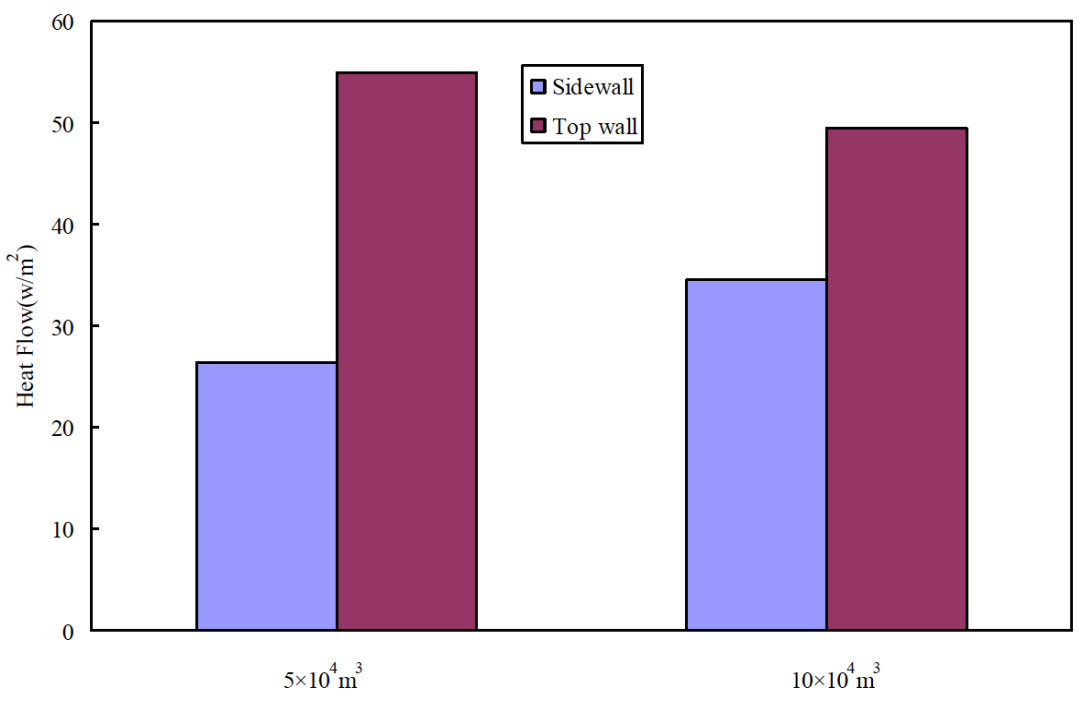

Fig. (15). Heat flow from sidewall and tank roof.

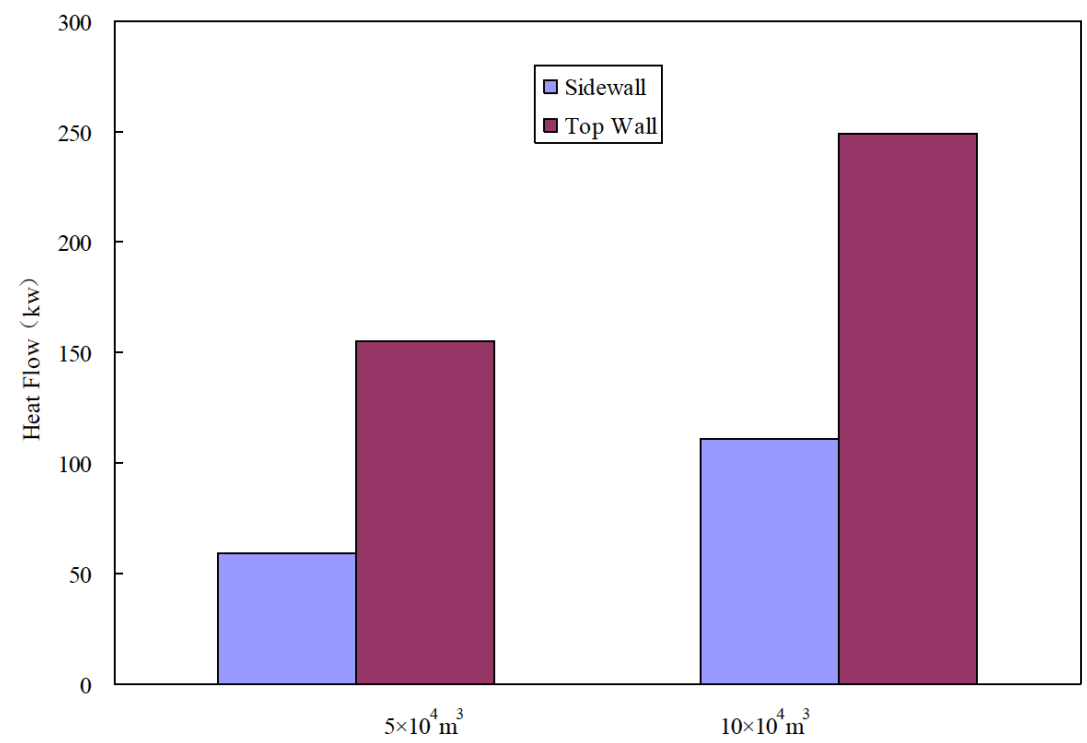

Fig. (16). Heat loss from sidewall and tank roof.

Table 6. Insulation effect of floating roof tank.

\begin{tabular}{|c|c|c|}
\hline $\begin{array}{c}\text { Specification } \\
\left(\mathbf{1 0}^{\mathbf{4}} \mathbf{m}^{\mathbf{3}}\right)\end{array}$ & $\begin{array}{c}\text { Top Wall Thermal } \\
\text { Conductivity } \\
(\mathbf{w} / \mathbf{m} \cdot \mathbf{K})\end{array}$ & $\begin{array}{c}\text { Sidewall Thermal } \\
\text { Conductivity } \\
(\mathbf{w} / \mathbf{m} \cdot \mathbf{K})\end{array}$ \\
\hline \hline 5 & 0.639 & 0.0364 \\
\hline 10 & 0.607 & 0.0495 \\
\hline
\end{tabular}

\section{HEAT LOSS ESTIMATE}

In case that the thermal conductivity of different parts is known, the heat loss of floating roof tank can be estimated. The ambient temperature, the specification of tank and the oil level are the main factors to determine the heat loss of the oil tank. Based on the energy balance theory, the heat loss of different oil tank in different environmental conditions is calculated. During the calculation, the thermal conductivity of tank roof is evaluated by $0.639 \mathrm{w} / \mathrm{m} \cdot \mathrm{K}$, and the thermal conductivity of sidewall is 0.0364 . And the initial oil temperature is $40^{\circ} \mathrm{C}$.

\subsection{The Heat Loss of Oil Tank in Different Specification}

Under the calculation, the level of each tank is $10 \mathrm{~m}$. According to the calculation data, the heat loss of different specification of oil tank has a larger difference between each other in the cold weather when the ambient temperature is $20^{\circ} \mathrm{C}$ Figs. $(17,18)$. The difference of heat loss decreases with the ambient temperature rising. At the same ambient temperature, due to the enlarged heat loss area of the tank roof and sidewall, the heat loss increases with the increasing of the tank capacity. Besides, due to the decreasing temperature difference between the oil and environment when the oil temperature decreases, the heat loss reduces with the time goes by. Although the heat loss enlarges with the increasing of the tank capacity, the change rule of heat loss for mass oil is different. Figs. $(\mathbf{1 9}, \mathbf{2 0})$ are the heat loss for unit mass oil at different ambient temperature. From these data, 


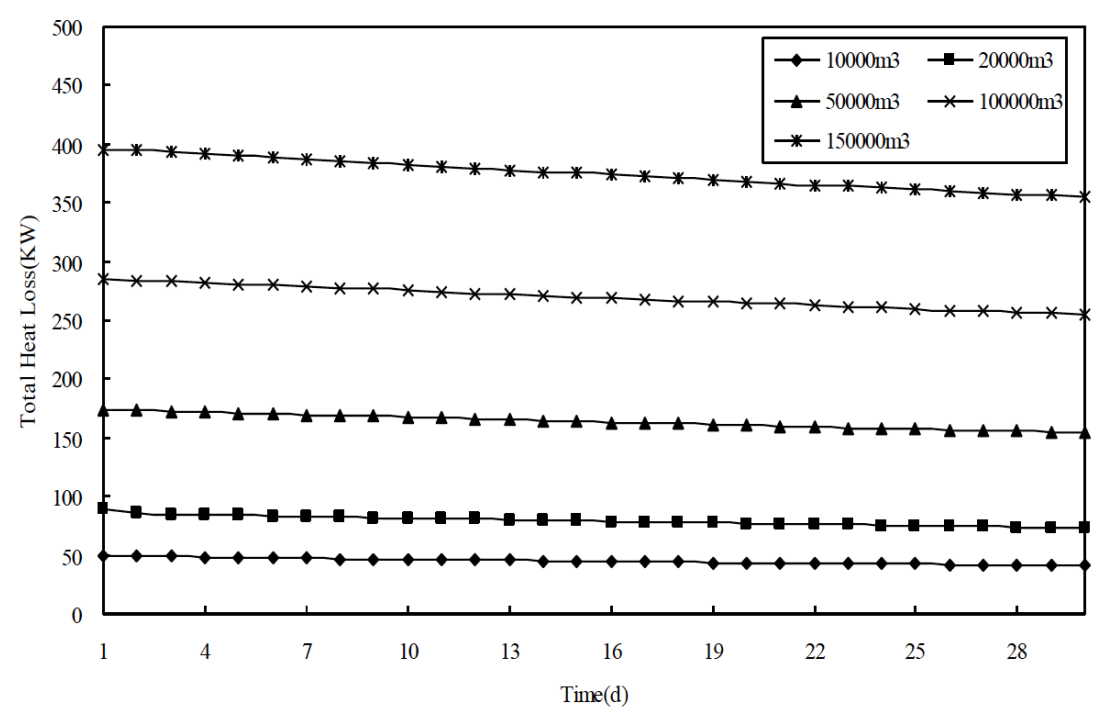

Fig. (17). Total heat loss of oil tank $\left(-20^{\circ} \mathrm{C}\right)$.

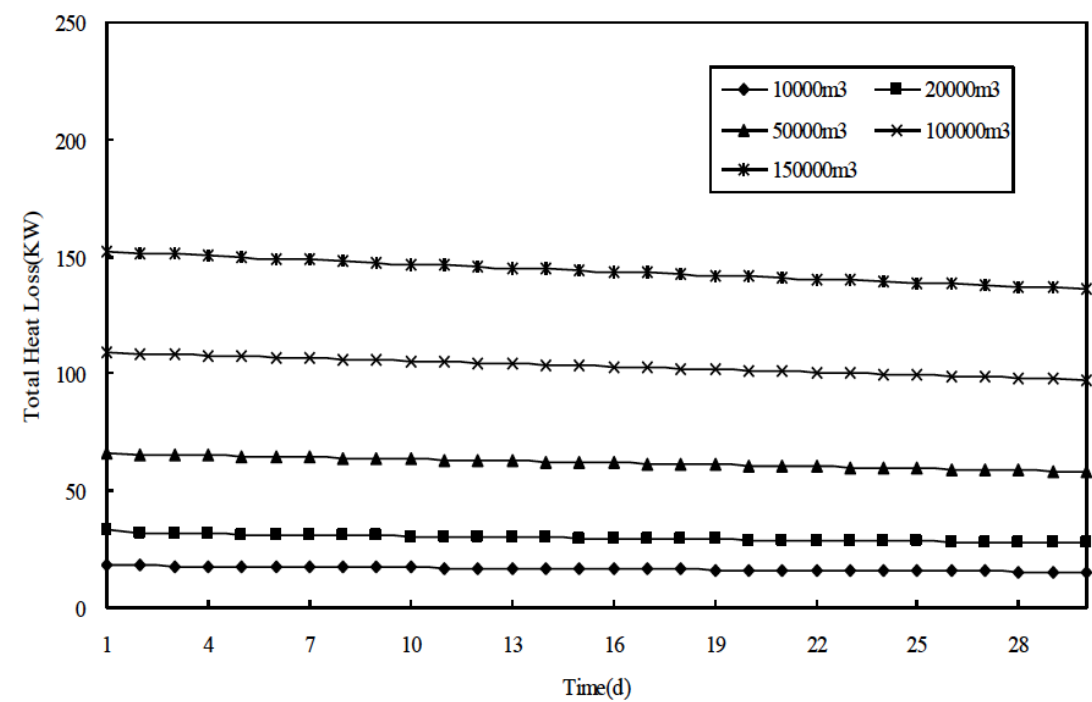

Fig. (18). Total heat loss of oil tank $\left(20^{\circ} \mathrm{C}\right)$.

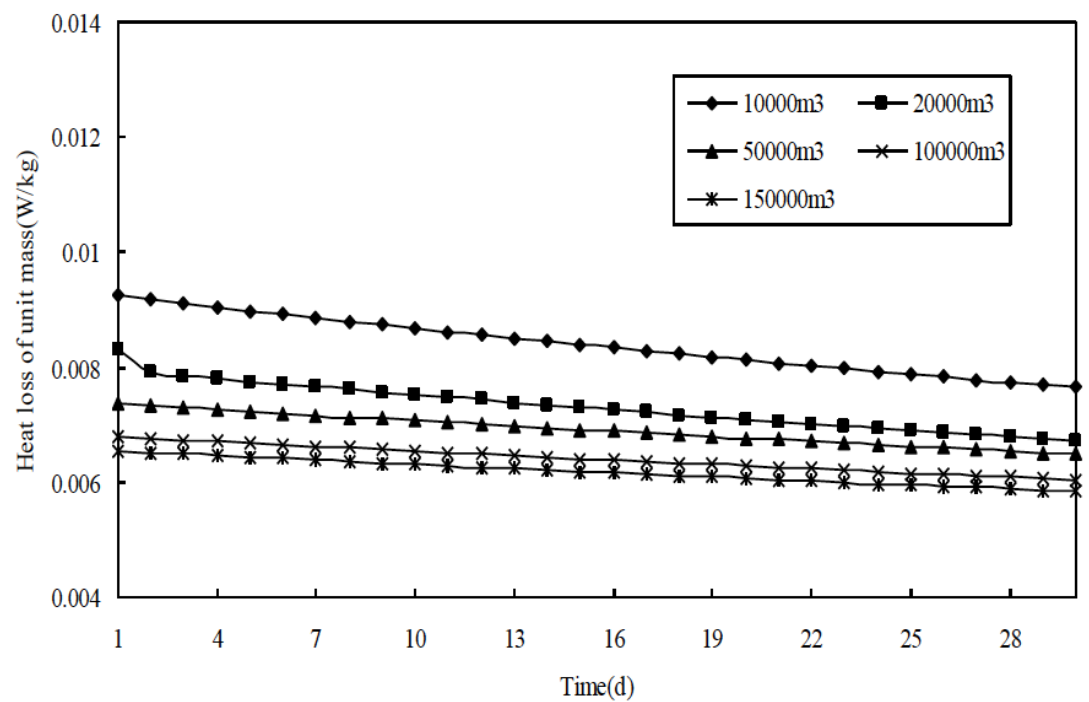

Fig. (19). Heat loss of unit mass oil $\left(-20^{\circ} \mathrm{C}\right)$. 


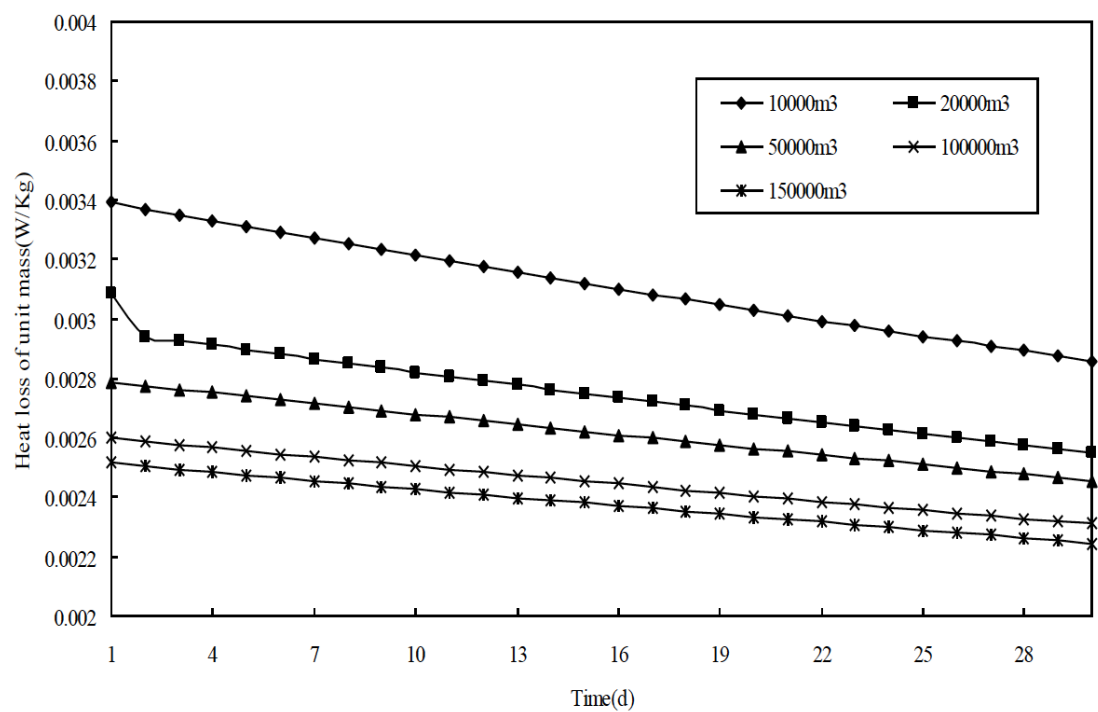

Fig. (20). Heat loss of unit mass oil $\left(20^{\circ} \mathrm{C}\right)$.

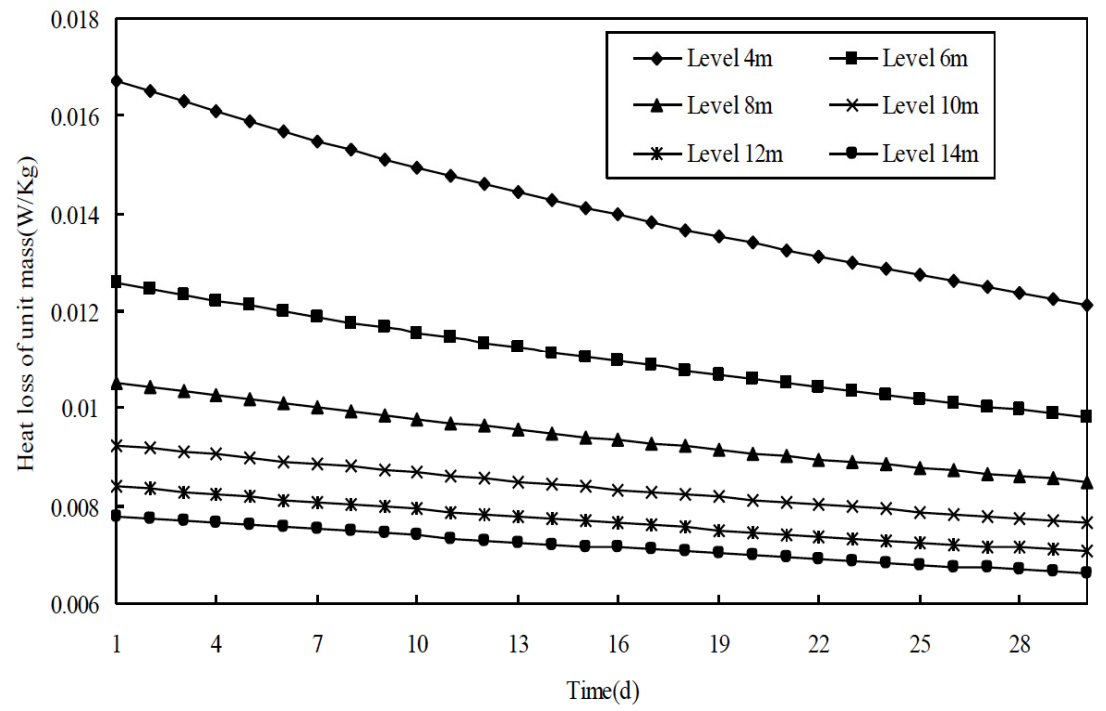

Fig. (21). Heat loss of unit mass oil $\left(1 \times 10^{4} \mathrm{~m}^{3}\right)$.

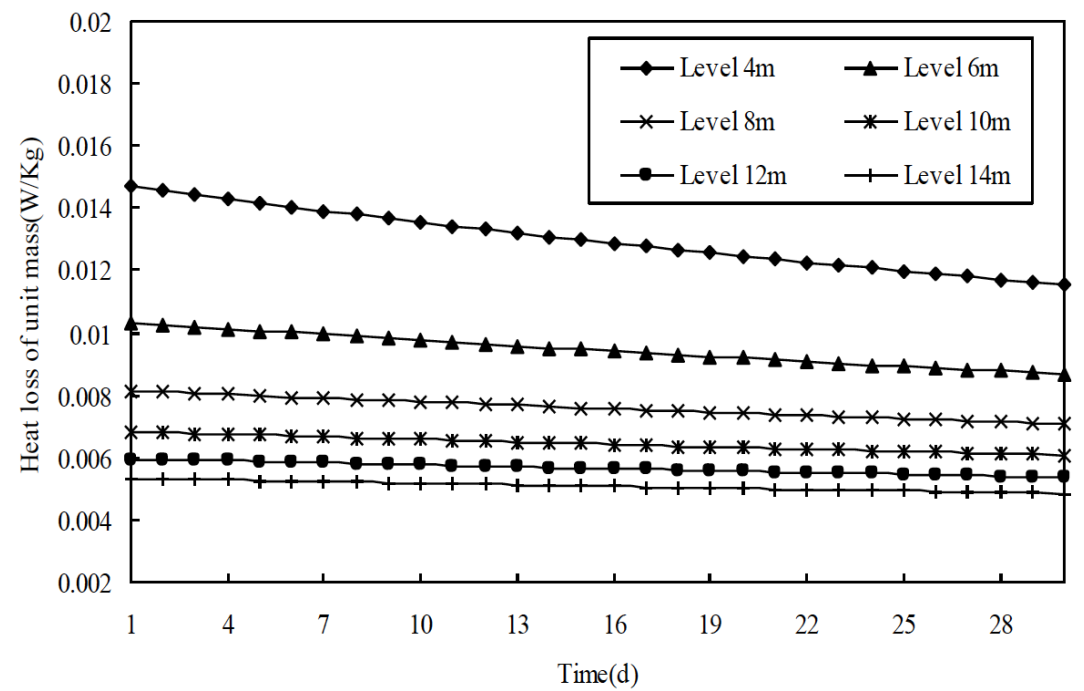

Fig. (22). Heat loss of unit mass oil $\left(10 \times 10^{4} \mathrm{~m}^{3}\right)$. 
the heat loss of unit mass oil decreases with the increasing of the tank capacity, which means the centralization storage of oil is a more energy conservation storage pattern.

\subsection{The Heat Loss of Oil Tank in Different Level}

In order to investigate the effect of tank level on the heat loss of floating roof tank, the levels $4 \mathrm{~m}, 6 \mathrm{~m}, 8 \mathrm{~m}, 10 \mathrm{~m}, 12 \mathrm{~m}$ and $14 \mathrm{~m}$ of $1 \times 10^{4}$ and $10 \times 10^{4}$ oil tank are calculated at the temperature of $-20^{\circ} \mathrm{C}$, the results are shown as follows Figs. (21, 22):

For the same capacity of tank, with the increasing of level, the oil temperature decreasing slower, leading the heat loss of unit mass oil decrease. Especially under the level of $6 \mathrm{~m}$, an obvious variation of heat loss can be seen. So the level of oil tank should be a little higher under the safety condition.

\section{CONCLUSION}

The heat loss and surface temperature from the top surface and sidewall of large-scale floating roof tank is tested by the heat flow meter and surface temperature method. Based on the test data, the heat loss from the top surface is about twice more than that of the sidewall which means the top surface is the weakest insulation part of the footing roof tank. On the surface, the heat loss profile is in accord with the surface temperature distribution. Special attention is given on the calculation of thermal conductivity of different walls which finally deducing the total heat transfer coefficient of large floating roof tank.

The tank capacity, the temperature gradient between oil and ambient, the level of oil is regarded as the main factors on the heat loss. From the calculation results under different conditions, the large capacity of oil tank corresponds to a higher heat loss. However, a lower heat loss of unit mass oil is got. The ambient temperature makes an obvious effect on the heat loss of oil tank. Besides, with the increasing of tank level, the heat loss decreases. The level of $6 \mathrm{~m}$ is regarded as a critical level determining the heat loss. In summary, the centralization storage of oil is a more energy conservation storage pattern.

\section{CONFLICT OF INTEREST}

The authors confirm that this article content has no conflict of interest.

\section{ACKNOWLEDGEMENTS}

This work is supported by PetroChina Innovation Foundation (2014D-5006-0607). In addition, the authors express gratitude to the Key Laboratory of Enhance Oil and Gas Recovery of Educational Ministry and The Transportation and Storage and Marketing Subsidiary Company of Daqing Oil Field for the support of the test work.

\section{REFERENCES}

[1] C. Busson, and C. Miniscloux, "Modele technoeconomique de calorifugeage des reservoirs de fuel lourd," Rev. Gen. Therm, vol. 226, pp. 785-797, 1980.

[2] J.D. Kumana, and S.P. Kothari, "Predict storage tank heat transfer precisely," Chem. Eng., vol. 6, pp. 127-132, 1982.

[3] J.E.S. Venart, A.C.M. Sousa, M. Laplante, and R. Pickles, "Free convective flows in large heated oil storage tanks", In: Proc. $7^{\text {th }}$ Int. Heat Trans. Conf., vol. 2, pp. 293-297, 1982.

[4] M. Cotter, and M. Charles, "Transient cooling of petroleum by natural convection in cylindrical storage tanks-I. Development and testing the numerical simulator", Int. J. Heat Mass Transfer, vol. 36, pp. 2165-2174, 1993.

[5] M. Cotter, and M. Charles, "Transient cooling of petroleum by natural convection in cylindrical storage tanks-II. Effect of heat transfer coefficient, aspect ratio and temperature-dependent viscosity," Int. J. Heat Mass Transfer, no. 36, pp. 2175-2182, 1993.

[6] M. Cotter, and M. Charles, "Transient cooling of petroleum by natural convection in cylindrical storage tanks: a Simplified Heat Loss Model," Can. J. Chem. Eng., vol. 70, pp. 1090-1093, 1992.

Received: December 15, 2014

Revised: January 04, 2015

Accepted: February 25, 2015

(C) Zhao et al.; Licensee Bentham Open.

This is an open access article licensed under the terms of the Creative Commons Attribution Non-Commercial License (http://creativecommons.org/licenses/by-nc/3.0/) which permits unrestricted, non-commercial use, distribution and reproduction in any medium, provided the work is properly cited. 